\title{
Distance saturation product predicts health-related quality of life among sarcoidosis patients
}

Julie M Bourbonnais, Subramanian Malaisamy, Bhavinkumar D Dalal, Priyan C Samarakoon, Swapna R Parikh and Lobelia Samavati*

\begin{abstract}
Background: Sarcoidosis is a chronic disease with different phenotypic manifestations. Health-related quality of life is an important aspect in sarcoidosis, yet difficult to measure. The objective of this study was to identify clinical markers predictive of poor quality of life in sarcoidosis patients that can be followed over time and targeted for intervention.

Methods: We assessed the quality of life of 162 patients with confirmed sarcoidosis in a prospective, cross-sectional study using the Sarcoidosis Health Questionnaire (SHQ) and Short Form-36 Health Survey (SF-36). We evaluated the validity of these questionnaires and sought to identify variables that would best explain the performance scores of the patients.

Results: On multivariate regression analyses, the very best composite model to predict total scores from both surveys was a model containing the distance-saturation product and Borg Dyspnea Scale score at the end of a 6 -min walk test. This model could better predict SF-36 scores $\left(R^{2}=0.33\right)$ than SHQ scores $\left(R^{2}=0.24\right)$. Substitution of distanced walked in 6 min for the distance-saturation product in this model resulted in a lesser ability to predict both scores $\left(R^{2}=0.26\right.$ for SF-36; $R^{2}=0.22$ for $\left.S H Q\right)$.

Conclusions: Both the SHQ and SF-36 surveys are valuable tools in the assessment of health-related quality of life in sarcoidosis patients. The best model to predict quality of life among these patients, as determined by regression analyses, included the distance-saturation product and Borg score after the 6-min walk test. Both variables represent easily obtainable clinical parameters that can be followed over time and targeted for intervention.
\end{abstract}

Keywords: Sarcoidosis, Health- related quality of life, 6-min walk test, Distance-saturation product

\section{Background}

Sarcoidosis is a chronic, multisystem disease with a highly variable natural history, prognosis, and response to treatment [1]. Symptoms may include cough, dyspnea, fatigue, and pain, all of which can be disabling and may impair the quality of life (QoL) [2].

Health-related quality of life (HRQoL) is defined as an individual's overall satisfaction with life and functional status as affected by the disease. Despite the complex nature of QoL, HRQoL measurements attempt to assess

\footnotetext{
* Correspondence: Isamavat@med.wayne.edu

Department of Medicine, Division of Pulmonary, Critical Care and Sleep,
Wayne State University School of Medicine and Detroit Medical Center,

Department of Medicine, Division of Pulmonary, Critical Care and Sleep,
Wayne State University School of Medicine and Detroit Medical Center, Detroit, MI 48201, USA
}

the impact of a disease and/or therapeutic intervention on QoL.

Measures of HRQoL are classified as either diseasespecific or generic [3-5]. Generic measures are considered less precise than disease-specific in their ability to assess the different aspects of a disease, but these measures may capture unanticipated side effects of therapies. Measures of HRQoL have been validated for multiple diseases, including sarcoidosis. However, there is also a need for reliable physiological measures that can reflect HRQoL. Identification of these parameters is important since modification of these variables through targeted interventions may improve the QoL of patients. 
There is a paucity of studies addressing physiologic predictors as surrogates for measurement of HRQoL. Several routine clinical measures, including pulmonary function tests (PFTs) and the 6-min walk test (6MWT), may serve such purpose. Previous studies have not consistently demonstrated strong correlation between HRQoL scores and the severity of airflow limitation in some respiratory diseases, such as chronic obstructive pulmonary disease (COPD) [6, 7]. Elements derived from the 6MWT have been shown to fairly accurately predict morbidity and mortality in a variety of heart and lung diseases and may represent a better predictor of HRQoL scores [8-18]. The distance-saturation product (DSP) is calculated from walking distance and the lowest oxygen saturation occurring during 6MWT [17]. The DSP was shown to be a better predictor of poor outcome in patients with idiopathic pulmonary fibrosis (IPF) than the individual elements used in its calculation [17].

The purpose of this study is to identify measurable clinical and physiological variables, which best correlate with HRQoL and can be followed over time for targeted intervention. We hypothesized that the measures derived from the $6 \mathrm{MWT}$ are a better predictor of HRQoL measures than are PFTs. Additionally, we postulate that DSP may be the most useful variable because it is a composite index and may more accurately reflect the multiorgan involvement of sarcoidosis.

\section{Methods}

Patients with sarcoidosis were prospectively recruited from the Sarcoidosis and Interstitial Lung Disease Clinic at Wayne State University/Detroit Medical Center in Detroit, Michigan. Sarcoidosis was diagnosed in all patients using standard guidelines [19]. Adult patients between 18 and 75 years with a biopsy proven diagnosis of sarcoidosis for more than 6 months were invited to participate between December 2005 and May 2008. Patients who were pregnant and those who were organ transplant recipients were excluded. Patients with known COPD, active cancer, or severe cardiomyopathy were excluded to avoid confounding comorbidities. Additionally, patients were excluded if they were not fluent in English or had physical impairments that prevented the completion of questionnaires. The Institutional Review Board of Wayne State University approved this study and all patients provided informed consent.

Variables analyzed included chest radiography, PFT and $6 \mathrm{MWT}$ data. Chest radiography was available for most patients and was interpreted as stage $0-4[19,20]$. PFTs were performed in a licensed laboratory following guidelines established by the American Thoracic Society [21]. All spirometry studies were performed as described previously [16]. Seventy nine percent of patients completed the
PFTs within 3 weeks (most within the same week), 16\% within 3 months, and less than 5\% within 6 months of completion of the questionnaires. All patients included in analyses completed at least one 6MWT, performed by a licensed respiratory therapist following a standardized protocol [22]. Oxygen saturation was measured using a finger probe pulse oximeter (NPB-40, Nellcor; Pleasanton, CA). All subjects demonstrated a resting saturation of more than $88 \%$ at initiation of testing. If the patients required oxygen, the oxygen flow was maintained at their baseline until completion of testing or adjusted based on titration on exertion during home oxygen evaluation. 6MWT data included Borg Dyspnea Scale score (BDSS), 6-min walk distance (6MWD), and oxygen saturation. The percent predicted 6MWD was calculated as described previously [23]. All $6 \mathrm{MWT}$ data were collected within 6 weeks of completion of the questionnaires.

All participants self-administered two questionnaires, the Sarcoidosis Health Questionnaire (SHQ) and the Medical Outcomes Study 36-item Short Form survey (SF-36) [3, 7, 24-29]. Using the online scoring system, the individual scores were normalized and these values were used for statistical analyses [30]. The SHQ is specific for sarcoidosis and has 29 questions with three domains: daily, physical and emotional functioning [4]. The scores were calculated as previously described [4].

Continuous variables are expressed as mean \pm SEM. Means were compared using the Student's $t$ test. Discrete variables were compared using Fisher exact test. Pearson correlation coefficient $(r)$ was calculated to measure the relationship between the clinical variables and total SHQ and SF-36 scores. Multivariate analyses were performed using a stepwise, descending method for factors with significance on univariate analyses. Data processing and analyses were performed using standard statistical software (SPSS for Windows, version 15.0). Statistical significance was defined as p value $<0.05$.

\section{Results}

One hundred and sixty two patients with a tissue proven diagnosis of sarcoidosis consented to participate in the study and completed both the SHQ and SF-36 questionnaires on the same day. Table 1 presents patient characteristics. The average age of study group was $46,76 \%$ were nonsmokers, $72 \%$ were female (117) and $86 \%$ were African American (139). The majority of patients had active disease (72\%), with $58 \%$ requiring steroid therapy and $42 \%$ requiring immune modulating medications. In 152 patients (94\%), pulmonary involvement was observed. Thirty-one patients (19\%) required oxygen supplementation.

Table 2 shows the results of PFT and 6MWT. One hundred fifty two patients had PFTs performed and 148 completed $6 \mathrm{MWTs}$ in the allotted time frame. The average 
Table 1 Patient characteristics

\begin{tabular}{llll}
\hline Age (Mean \pm SD) & $\mathbf{4 5 . 9} \pm \mathbf{1 1 . 1}$ & Disease, N (\%) & $45(28)$ \\
\hline BMI (Mean \pm SD) & $32 \pm 8.2$ & Inactive & $117(72)$ \\
Gender, N (\%) & & Active/Symptomatict & $152(94)$ \\
Male & $45(28)$ & Organ Involvements N (\%) \\
Female & $117(72)$ & Lung & $49(30)$ \\
Race, N (\%) & & Skin & $43(26)$ \\
African American & $139(86.8)$ & Eye & $11(6)$ \\
White & $21(13.2)$ & Heart & $18(11)$ \\
CXR stage, N (\%) & & Liver \\
0 & $13(8.2)$ & CNS & $13(6)$ \\
1 & $28(17.7)$ & PH* & $28(17)$ \\
2 & $65(41.5)$ & Medication, N (\%) & \\
3 & $24(14)$ & Steroidal & $94(58)$ \\
4 & $29(18.2)$ & IMD* & $68(42)$ \\
Non-smokers & $123(76)$ & Steroidal + IMD & $77(47)$
\end{tabular}

Values are means unless otherwise noted. $\mathrm{N}=$ number of patients, parenthesis $=$ percent.

*PH: pulmonary hypertension, diagnosed by right cardiac catheterization. † Active defined as an increased requirement for steroid in last 6 months. + Immune modifying drugs like methotrexate, azathioprine and others.

distance walked was $427 \mathrm{~m} \pm 106 \mathrm{~m}$ (range $105 \mathrm{~m}$ to $690 \mathrm{~m}$ ). The DSP is a product of the walking distance at $6 \mathrm{~min}$ and the lowest oxygen saturation achieved during the $6 \mathrm{MWT}$ [17]. The average DSP was $402 \mathrm{~m} \% \pm 108 \mathrm{~m} \%$ (range $103 \mathrm{~m} \%$ to $662 \mathrm{~m} \%$ ).

The average SHQ score was $3.8 \pm 1.1$ and the average SF-36 score was $45 \pm 26$. Using Pearson correlation, we compared the validity of the SHQ with SF-36 questionnaires and their relationship was found to be significant in all domains. Pearson correlation coefficients ranged from a low of 0.72 for SF-36 Physical Component Score

Table 2 PFTs and 6-min Walk Test (6MWT)

\begin{tabular}{ll}
\hline Variables & Mean \pm SD (range) \\
\hline PFTs (N = 152) & $72 \pm 20(21-117)$ \\
FEV1\% & $72 \pm 18(33-113)$ \\
FVC\% & $79 \pm 17(43-137)$ \\
TLC\% & $62 \pm 19(21-107)$ \\
DLCO\% & \\
6MWT (N= 148) & $427 \pm 106(105-690)$ \\
6 MWD (m) & $75 \pm 17(23-111)$ \\
6 MWD (\%) & $97 \pm 2(90-100)$ \\
Oxygen saturation at 0 min & $93 \pm 4.5(78-100)$ \\
Oxygen saturation at 6 min & \\
Borg Score (N= 148) & $1.7 \pm 1.7(0-7)$ \\
Borg at 0 min & $4.4 \pm 2.3(1-10)$ \\
Borg at 6 min & $402 \pm 108(103-662)$ \\
DSP (N = 148) (m\%)
\end{tabular}

$\mathrm{N}=$ Number of patients.
(PCS) to a high of 0.78 for total score. Student's $t$ test was used to compare the mean performance scores of SHQ and SF-36 for patients with pulmonary hypertension $(\mathrm{PH})$ and patients without $\mathrm{PH}$. Patients with $\mathrm{PH}$ demonstrated significantly lower scores $(\mathrm{p}<0.05)$ in total SF-36 $(33 \pm 12)$ as compared to those without $\mathrm{PH}$ $(45 \pm 26)$. The SF-36 PCS scores between groups were significantly different, $30 \pm 2.7$ for $\mathrm{PH}$ versus $39 \pm 13$ for patients without $\mathrm{PH}(\mathrm{p}=0.007)$. Surprisingly, there were no significant differences in the total SHQ scores between these two groups.

Pearson correlation was used to measure the relationship between several clinical variables, the total SHQ and SF-36 scores (Table 3). The most significant correlations were found with elements derived from 6MWT data. The highest correlation was found between DSP and HRQoL scores as assessed by SF-36 $(r=0.47, p$ $<0.01)$ or SHQ $(r=0.35, \mathrm{p}<0.01)$, respectively. The second best correlation was found between the BDSS at completion of the 6MWT and the total SF-36 score $(\mathrm{r}=-0.45, \mathrm{p}<0.01)$ and the total SHQ score $(\mathrm{r}=-0.42, \mathrm{p}$ $<0.01)$. There was a lesser correlation between the $6 \mathrm{MWD}$ and the surveys $(\mathrm{r}=0.42, \mathrm{p}<0.01$ for SF-36 and $\mathrm{r}=0.34 \mathrm{p}<0.01$ for SHQ) and for oxygen saturation at completion of $6 \mathrm{MWT}(\mathrm{r}=0.26, \mathrm{p}<0.01$ for SF-36 and $\mathrm{r}=0.22, \mathrm{p}<0.01$ for SHQ). Table 3 indicates all variables analyzed had a smaller correlation with HRQoL scores as measured by SHQ than by SF-36.

Overall, PFT values had a smaller correlation with the HRQoL measures as compared to 6MWT values. The highest correlations observed between SF-36 scores and PFT values, were $\mathrm{DL}_{\mathrm{CO}}(\mathrm{r}=0.34, \mathrm{p}<0.01), \quad \mathrm{FEV}_{1}$ $(\mathrm{r}=0.26, \mathrm{p}<0.01)$ and FVC $(\mathrm{r}=0.26, \mathrm{p}<0.01)$. Interestingly, all PFT values demonstrated lower correlations with total SHQ scores (see Table 3).

On univariate analyses $\mathrm{FEV}_{1}, \mathrm{DL}_{\mathrm{CO}}, \mathrm{BDSS}$ at 0 and $6 \mathrm{~min}, 6 \mathrm{MWD}$ and DSP were found to have a statistically significant relationship with questionnaire scores. Multivariate regression analyses were performed using

Table 3 Correlation between Total SF-36 and Total SHQ Scores and Physiologic Variables

\begin{tabular}{|c|c|c|c|c|}
\hline \multirow[b]{2}{*}{ Variable } & \multicolumn{2}{|c|}{ Total SHQ Score } & \multicolumn{2}{|c|}{ Total SF -36 Score } \\
\hline & $r$-value & $p$-value & $r$-value & p-value \\
\hline Borg at $6 \mathrm{~min}$ & $-0.42 * *$ & $<0.01$ & $-0.45^{* *}$ & $<0.01$ \\
\hline DSP & $0.35^{* *}$ & $<0.01$ & $0.47 * *$ & $<0.01$ \\
\hline 6MWD (m) & $0.34 * *$ & $<0.01$ & $0.37^{* *}$ & $<0.01$ \\
\hline Borg at $0 \mathrm{~min}$ & $0.31 * *$ & $<0.01$ & $0.374^{* *}$ & $<0.01$ \\
\hline 02 sat at $6 \mathrm{~min}$ & $0.23 * *$ & $<0.01$ & $0.26 * *$ & $<0.01$ \\
\hline $\mathrm{DL}_{\mathrm{co}}(\mathrm{L} \mathrm{mmHg} / \mathrm{min})$ & $0.30 * *$ & $<0.01$ & $0.34 * *$ & $<0.01$ \\
\hline FEV1(L) & $0.12 *$ & $<0.01$ & $0.26 * *$ & $<0.01$ \\
\hline
\end{tabular}

** Correlation is significant at $<0.01$ level (2-tailed test).

* Correlation is significant at $<0.05$ level (2-tailed test). 
these significant variables. Because DSP is a derived value from 6MWD, there is a high correlation between these two independent variables. To obtain the best linear unbiased estimators, four sets of multivariate regression models were estimated. Regression analysis using DSP with other independent variables as determined by univariate analysis was conducted for both SF-36 and SHQ to evaluate for the best model to account for the scores of both measures. Estimated regression models are reported in Table 4. After adjusting for age and BMI, the only two variables that remained significant and could reliably predict the HRQoL scores as measured by SF-36 $\left(\mathrm{R}^{2}=0.33\right)$ were DSP $(\mathrm{p}<0.01$; 95\% CI: 0.082 $0.02)$ and BDSS at $6 \min (p=0.049,95 \%$ CI: -2.18 to 1). When SHQ was used as the dependent variable, similar results were found but with a lower $\mathrm{R}^{2}$ value of 0.24 (DSP: $\mathrm{p}<0.01,95 \% \mathrm{CI}: 0.002-0.001$; BDSS at $6 \mathrm{~min} \mathrm{p}$ $<0.01,95 \%$ CI: -0.27 to -0.05$)$. No other explanatory variables were found to be significant. The results of the regression analyses substituting 6MWD for DSP are shown in Table 5 . Table 5 indicates that only 6MWD (p $<0.01)$ and BDSS $(\mathrm{p}=0.04)$ were significant and could reliably predict the HRQoL scores as measured by SF-36 $\left(R^{2}=0.26\right)$. Substituting SHQ for SF-36 scores, resulted in similar findings but with a lower $R^{2}$ value of 0.22 (6MWD, $\mathrm{p}=0.01$, Borg at $6 \min \mathrm{p}=0.02$ ).

\section{Discussion}

Several studies demonstrated poor HRQoL in patients with respiratory diseases including sarcoidosis $[2,6,7$, 24-26, 29, 31-36]. Using two commonly employed health related questionnaires we assessed the QoL of patients with sarcoidosis and attempted to identify the physiologic parameters that best predict QoL measures. Through statistical modeling, we determined that the best prediction of QoL scores can be achieved by integration of two simple values obtained from the 6MWT: DSP and BDSS at 6 min. Substitution of DSP value with 6MWD in the very same regression model resulted in a lower $\mathrm{R}^{2}$. Others found a relationship between $6 \mathrm{MWD}$ and HRQoL measures [18]. In our data set, oxygen

Table 4 Linear Regression DSP Multivariate Analysis with SHQ and SF-36

\begin{tabular}{|c|c|c|c|c|}
\hline \multirow[b]{2}{*}{ Variable } & \multicolumn{2}{|c|}{ Total SHQ Score } & \multicolumn{2}{|c|}{ Total SF -36 Score } \\
\hline & $p$ value & $95 \% \mathrm{Cl}$ & $p$ value & $95 \% \mathrm{Cl}$ \\
\hline DLCO & 0.9 & $-0.01-0.02$ & 0.5 & $-2.1-3.66$ \\
\hline FEV1 & 0.7 & $-0.52-0.16$ & 0.5 & $-2.2-0.44$ \\
\hline DSP & $0.009 *$ & $0.002-0.001$ & $<0.001 *$ & $0.082-0.02$ \\
\hline Borg at $0 \mathrm{~min}$ & 0.9 & $-0.06-0.7$ & 0.14 & $-2.2-1.6$ \\
\hline \multirow[t]{2}{*}{ Borg at $6 \mathrm{~min}$} & $<0.01 *$ & $-0.27-(-0.05)$ & $0.049 *$ & $-2.18-(-1)$ \\
\hline & \multicolumn{2}{|l|}{$R^{2}=0.24$} & \multicolumn{2}{|l|}{$R^{2}=0.33$} \\
\hline
\end{tabular}

* Suggests statistically significant.
Table 5 Linear Regression Multivariate Analysis with SHQ and SF-36

\begin{tabular}{|c|c|c|c|c|}
\hline \multirow[b]{2}{*}{ Variable } & \multicolumn{2}{|c|}{ Total SHQ Score } & \multicolumn{2}{|c|}{ Total SF -36 Score } \\
\hline & $p$ value & $95 \% \mathrm{Cl}$ & $p$ value & $95 \% \mathrm{Cl}$ \\
\hline DLCO & 0.6 & $-0.3-0.43$ & 0.5 & $-2.1-3.66$ \\
\hline FEV1 & 0.8 & $-0.33-0.26$ & 0.6 & $-8.4-5.4$ \\
\hline 6MWD & $0.01 *$ & $0.01-0.04$ & $<0.01 *$ & $0.031-0.1$ \\
\hline Borg at $0 \mathrm{~min}$ & 0.9 & $-0.15-0.13$ & 0.2 & $-5.5-0.16$ \\
\hline \multirow{2}{*}{ Borg at $6 \mathrm{~min}$} & $0.02 *$ & $-0.06-(-0.26)$ & $0.04 *$ & $-4.3-(-0.16)$ \\
\hline & \multicolumn{2}{|c|}{$R^{2}=0.22$} & \multicolumn{2}{|l|}{$R^{2}=0.26$} \\
\hline
\end{tabular}

* Suggests statistically significant.

saturation at 6 min did correlate with HRQoL measures in addition to PFT values, especially $\mathrm{DL}_{\mathrm{CO}}$ (data not shown). The DSP is a calculation derived from 6MWD and the lowest saturation at $6 \mathrm{~min}$ and has been shown to predict poor outcome in patients with IPF [17]. We conclude that HRQoL can best be predicted by DSP and the BDSS at 6 min and that these two parameters may be used as surrogates for HRQoL measures as determined by these two commonly used questionnaires. The $6 \mathrm{MWT}$ and dyspnea scores have previously been shown to be correlated to improvements in HRQoL scores [18, $32,37,38]$. A previous report addressed the reproducibility of the 6MWT among patients with fibrotic lung diseases and found that 6MWD is fairly reproducible. Interestingly, although the amplitude of desaturation among those patients varied, survival among those patients best correlated with the amplitude of oxygen desaturation as the strongest predictor of mortality [39]. The results of our study clearly demonstrate a significant relationship between DSP and HRQoL scores as determined by either SF-36 or SHQ and that DSP is a better predictor as compared with 6MWD.

Assessment of dyspnea is an important factor in evaluating the functional status of patients with diverse diseases and it has high impact on HRQoL scores [6, 37, 38]. Our findings concur with previous studies. Since exercise training and pulmonary rehabilitation may increase exercise capacity, reduce dyspnea and increase distance walked, these variables can be targeted for intervention and may impact positively on outcomes and HRQoL [37, 38].

Questionnaires designed to evaluate HRQoL have been validated and have been shown to improve patientphysician communication and counseling regarding aspects of QoL [40]. Previous studies have found that PFT values are not reliable markers to predict $\mathrm{HRQOL}$ in patients with COPD $[6,7,31]$. In the current study, $\mathrm{FEV}_{1}$, $\mathrm{FVC}$ and $\mathrm{DL}_{\mathrm{CO}}$ were found to have significant associations with HRQoL scores on univariate analyses, but not in the multiple regression models. No association was found between HRQoL scores and steroid use in our study, in 
contradiction to earlier studies [33-35]. Patients with obesity have also been shown to have poor HRQoL scores, but no statistically significant association was found between BMI and the HRQoL scores in our study [36, 41].

The SHQ is the only questionnaire specifically designed to assess HRQoL in patients with sarcoidosis. It was originally devised and validated with the SF-36 by Cox et al. [4]. Our study independently validated the SHQ with the SF-36 in a large cohort of patients with sarcoidosis. Additionally, we compared the different domains assessed by both questionnaires and found that the SHQ-PS correlated well with SF-36-PCS, as did the SHQ-ES score with SF-36-MCS. Because of its disease-specific nature, we hypothesized that the SHQ would be a better measure of HRQoL than the SF-36 in sarcoidosis patients. However, this hypothesis was not supported by the evidence reported here. One possibility is that the SHQ is differently weighted in regard to organ involvement as compared with SF-36. SHQ would likely perform better than a respiratory-specific measure of HRQoL, but we did not include this type of questionnaire in our study.

QoL is not only affected by disease severity, but also by the social and occupational limitations imposed by the disease. Ethnicity may impact QoL in conditions like sarcoidosis due to its influence on both disease severity and access to healthcare [42]. One limitation of this study is that the sample consists almost entirely of African American women. Because of minimal variation in ethnicity there may be racial differences not detected from this data set.

This study is also limited by the fact that we could not account for all comorbid conditions, including $\mathrm{PH}$, which may affect patients with sarcoidosis. Among the study patients, $17 \%$ had known $\mathrm{PH}$ as confirmed by right-sided cardiac catheterization (See Table 1). Recently, we have shown that a decreased oxygen saturation level at completion of 6MWT is highly predictive of the presence $\mathrm{PH}$ in patients with sarcoidosis [16]. These patients also tend to have a lower oxygen saturation resulting in a lower DSP. Additionally, we have not assessed fatigue in this study, which has been shown to be an important component of HRQoL and may impact the 6MWD [43]. Overall, the correlation of HRQoL measures and PFT values was lower as compared to correlation of those measures with values derived from 6MWTs. This finding is not entirely surprising. Due to the systemic nature of sarcoidosis, other systemic involvements, besides lung function, such as musculoskeletal involvement or fatigue may have contributed to the decrease in HRQoL measures. Finally, logistically we could not always obtain the PFT, 6MWT and questionnaires on the same day because of operational constraints at our institution. This might be considered a limitation of our study; although, it is unlikely that within weeks PFT values or $6 \mathrm{MWTwould}$ have changed to the extent that have influenced the results.

Our study is unique in attempting to identify commonly used clinical parameters as surrogate markers to predict HRQoL in chronic sarcoidosis. The DSP and BDSS at $6 \mathrm{~min}$ showed a significant association with HRQoL scores and, therefore, may be used to predict HRQoL in patients with sarcoidosis. These parameters may serve as potential targets for intervention to improve HRQoL. Further study is needed to validate the value of DSP as a universal measure for the assessment of HRQoL in other chronic respiratory diseases that lead to oxygen desaturation during exertion, such as COPD and IPF.

\section{Conclusions}

In conclusion, this study is among the first to identify markers to predict HRQoL in patients with sarcoidosis. The DSP and BDSS at 6 min are both easily obtained from the 6MWT. This will allow clinicians to identify patients who likely have poor HRQoL from an easily performed clinical test and to target these variables for intervention.

\section{Abbreviations}

6MWD: Six-minute walk distance; 6MWT: Six-minute walk test; BDSS: Borg Dyspnea Scale score; BMI: Body-mass index; COPD: Chronic obstructive pulmonary disease; $\mathrm{DL}_{\mathrm{CO}}$ : Diffusing capacity of carbon monoxide;

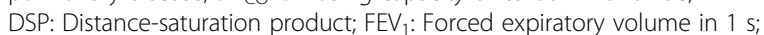
FVC: Forced vital capacity; HRQoL: Health-related quality of life; IPF: Idiopathic pulmonary fibrosis; PFT: Pulmonary function test; $\mathrm{PH}$ : Pulmonary hypertension; QoL: Quality of life; SF-36: Short Form-36 Health Survey; SF-36MCS: Short Form-36 Health Survey Mental Component Score; SF-36PCS: Short Form-36 Health Survey Physical Component Score; SHQ: Sarcoidosis Health Questionnaire; SHQ-ES: Sarcoidosis Health Questionnaire - Emotional Score; SH-PS: Sarcoidosis Health Questionnaire Physical Score.

\section{Competing interests}

No conflicts of interest were identified by any of the authors. No sources provided support in the form of grants, gifts, equipment, and/or drugs to any of the authors involved in this publication.

\section{Authors' contributions}

JMB participated in design of the study and drafted the manuscript. SM participated in data collection and in drafting the manuscript. BDD performed statistical analysis. PCS and SRP participated in design of the study and data collection. LS conceived of the study, participated in its design and coordination, performed statistical analysis and helped draft the manuscript.

Received: 3 January 2012 Accepted: 13 June 2012 Published: 13 June 2012

\section{References}

1. Wasfi YS, Rose CS, Murphy JR, Silveira L, Grutters JC, Inoue Y, Judson MA, Maier LA: A new tool to assess sarcoidosis severity. Chest 2006, 129:1234-1245.

2. De Vries J, Drent M: Quality of life and health status in sarcoidosis: a review. Semin Respir Crit Care Med 2007, 28:121-127.

3. Ware JE Jr, Sherbourne CD: The MOS 36-item short-form health survey (SF-36). I. Conceptual framework and item selection. Med Care 1992, 30:473-483 
4. Cox CE, Donohue JF, Brown CD, Kataria YP, Judson MA: The Sarcoidosis Health Questionnaire: a new measure of health-related quality of life. Am J Respir Crit Care Med 2003, 168:323-329.

5. Jones PW, Quirk FH, Baveystock CM, Littlejohns P: A self-complete measure of health status for chronic airflow limitation. The St. George's Respiratory Questionnaire. Am Rev Respir Dis 1992, 145:1321-1327.

6. Geijer RM, Sachs AP, Verheij TJ, Kerstjens HA, Kuyvenhoven MM, Hoes AW: Quality of life in smokers: focus on functional limitations rather than on lung function? Br J Gen Pract 2007, 57:477-482.

7. Kaplan RM, Ries AL: Quality of life as an outcome measure in pulmonary diseases. J Cardpulm Rehabil 2005, 25:321-331.

8. Cahalin LP, Mathier MA, Semigran MJ, Dec GW, DiSalvo TG: The six-minute walk test predicts peak oxygen uptake and survival in patients with advance heart failure. Chest 1996, 110:325-332.

9. Hallstrand TS, Boitano LJ, Johnson WC, Spada CA, Hayes JG, Raghu G: The timed walk test as a measure of severity and survival in idiopathic pulmonary fibrosis. Eur Respir J 2005, 25:96-103.

10. Miyamoto S, Nagaya N, Satoh T, Kyotani S, Sakamaki F, Fujita M, Nakanishi N, Miyatake K: Clinical correlates and prognostic significance of sixminute walk test in patients with primary pulmonary hypertension. Comparison with cardiopulmonary exercise testing. Am J Respir Crit Care Med 2000, 161:487-492.

11. Kadikar A, Maurer J, Kesten S: The six-minute walk test: a guide to assessment for lung transplantation. J Heart Lung Transplant 1997, 16:313-319.

12. Lederer DJ, Arcasoy SM, Wilt JS, D'Ovidio F, Sonett JR, Kawut SM: Sixminute-walk distance predicts waiting list survival in idiopathic pulmonary fibrosis. Am J Respir Crit Care Med 2006, 174:659-664.

13. Paciocco G, Martinez FJ, Bossone E, Pielsticker E, Gillespie B, Rubenfire M: Oxygen desaturation on the six-minute walk test and mortality in untreated primary pulmonary hypertension. Eur Respir J 2001, 17:647-652.

14. Flaherty KR, Andrei AC, Murray S, Fraley C, Colby TV, Travis WD, Lama V, Kazerooni EA, Gross BH, Toews GB, Martinez FJ: Idiopathic pulmonary fibrosis: prognostic values of changes in physiology and six-minute-walk test. Am J Respir Crit Care Med 2006, 174:803-809.

15. Lama VN, Flaherty KR, Toews GB, Colby TV, Travis WD, Long Q, Murray S, Kazerooni EA, Gross BH, Lynch JP 3rd, Martinez FJ: Prognostic value of desaturation during a 6-minute walk test in idiopathic interstitial pneumonia. Am J Respir Crit Care Med 2003, 168:1084-1090.

16. Bourbonnais JM, Samavati L: Clinical predictors of pulmonary hypertension in sarcoidosis. Eur Respir J 2008, 32:296-302.

17. Lettieri CJ, Nathan SD, Browning RF, Barnett SD, Ahmad S, Shorr AF: The distance-saturation product predicts mortality in idiopathic pulmonary fibrosis. Respir Med 2006, 100:1734-1741.

18. Baughman RP, Sparkman BK, Lower EE: Six-minute walk test and health status assessment in sarcoidosis. Chest 2007, 132:207-213.

19. Statement on sarcoidosis: Joint statement of the American Thoracic Society (ATS), the European Respiratory Society (ERS) and the World Association of Sarcoidosis and Other Granulomatous Disorders (WASOG) adopted by the ATS Board of Directors and by the ERS Executive Committee, February 1999. Am J Respir Crit Care Med 1999, 160:736-755.

20. Scadding JG: Prognosis of intrathoracic sarcoidosis in England. A review of 136 cases after five years' observation. Br Med J 1961, 5261:1165-1172.

21. Brusasco V, Crapo R, Viegi G: ATS/ERS Task Force: Standardization of lung function testing. Eur Respir J 2005, 26:319-338

22. ATS Committee on Proficiency Standards for Clinical Pulmonary Function Laboratories: ATS statement: guidelines for the six-minute walk test. Am J Respir Crit Care Med 2002, 166:111-117.

23. Enright PL, Sherrill DL: Reference equations for six-minute walk in healthy adults. Am J Respir Crit Care Med 1998, 158:1384-1387.

24. Mahler DA, Mackowiak Jl: Evaluation of the short-form 36-item questionnaire to measure health-related quality of life in patients with COPD. Chest 1995, 107:1585-1589.

25. Martinez TY, Pereira CA, dos Santos ML, Ciconelli RM, Guimaraes SM, Martinez JA: Evaluation of the short-form 36-item questionnaire to measure health-related quality of life in patients with idiopathic pulmonary fibrosis. Chest 2000, 117:1627-1632.

26. Chang JA, Curtis JR, Patrick DL, Raghu G: Assessment of health-related quality of life in patients with interstitial lung disease. Chest 1999, 116:1175-1182.
27. Ruta DA, Hurst NP, Kind P, Hunter M, Stubbings A: Measuring health status in British patients with rheumatoid arthritis: reliability, validity and responsiveness of the short form 36-item health survey. Br J Rheumatol 1998, 37:425-436.

28. Bonkovsky HL, Snow KK, Malet PF, Back-Madruga C, Fontana RJ, Sterling RK, Kulig CC, Di Bisceglie AM, Morgan TR, Dienstag JL, Ghany MG, Gretch DR, HALT-C Trial Group: Health-related quality of life in patients with chronic hepatitis C and advanced fibrosis. J Hepatol 2007, 46:420-431.

29. Girard F, Chouinard P, Boudreault D, Poirier C, Richard C, Ruel M, Ferraro P: Prevalence and impact of pain on the quality of life of lung transplant recipients: a prospective observational study. Chest 2006, 130:1535-1540.

30. : The SF Community - offering information and discussion on health outcomes. Scoring and interpreting data.: ; http://www.sf-36.org.

31. Gross NJ: Chronic obstructive pulmonary disease outcome measurements: What's important? What's useful? Proc Am Thorac Soc 2005, 2:267-271

32. Kaplan RM, Ries AL: Health-related quality of life in emphysema. Proc Am Thorac Soc 2008, 5:561-566.

33. Güneylioğlu D, Ozşeker F, Bilgin S, Kucuk CU, Akkaya E: The influence of sarcoidosis on quality of life. Tuberrk Toraks 2004, 52:31-37.

34. Cox CE, Donohue JF, Brown CD, Kataria YP, Judson MA: Health-related quality of life of persons with sarcoidosis. Chest 2004, 125:997-1004.

35. Michielsen HJ, Peros-Golubicic T, Drent M, De Vries J: Relationship between symptoms and quality of life in a sarcoidosis population. Respiration 2007, 74:401-405

36. Michielsen HJ, Drent M, Peros-Golubicic T, De Vries J: Fatigue is associated with quality of life in sarcoidosis patients. Chest 2006, 130:989-994.

37. von Leupoldt A, Hahn E, Taube K, Schubert-Heukeshoven S, Magnussen H, Dahme B: Effects of 3-week outpatient pulmonary rehabilitation on exercise capacity, dyspnea, and quality of life in COPD. Lung 2008, 186:387-391.

38. Puhan MA, Scharplatz M, Troosters T, Steurer J: Respiratory rehabilitation after acute exacerbation of COPD may reduce risk for readmission and mortality - a systematic review. Respir Res 2005, 6:54.

39. Eaton T, Young $P$, Milne D, Wells AU: Six-minute walk, maximal exercise trests: Reproducibilty in fibrotic interstitial pneumonia. Am J Respir Crit Care Med 2005, 171:1150-1157.

40. Detmar SB, Muller MJ, Schornagel JH, Wever LD, Aaronson NK: Healthrelated quality-of-life assessments and patient-physician communication: a randomized controlled trial. JAMA 2002, 288:3027-3034.

41. Groessl EJ, Kaplan RM, Barrett-Connor E, Ganiats TG: Body mass index and quality of well-being in a community of older adults. Am J Prev Med 2004, 26:126-129.

42. Kelley E, Moy E, Stryer D, Burstin H, Clancy C: The national healthcare quality and disparities reports: an overview. Med Care 2005, 43:13-18.

43. DeVries J, Lower EE, Drent M: Quality of life in sarcoidosis: assessment and management. Semin Respir Crit Care Med 2010, 31:485-493.

\section{doi:10.1186/1477-7525-10-67}

Cite this article as: Bourbonnais et al:: Distance saturation product predicts health-related quality of life among sarcoidosis patients. Health and Quality of Life Outcomes 2012 10:67.

\section{Submit your next manuscript to BioMed Central and take full advantage of:}

- Convenient online submission

- Thorough peer review

- No space constraints or color figure charges

- Immediate publication on acceptance

- Inclusion in PubMed, CAS, Scopus and Google Scholar

- Research which is freely available for redistribution 